\title{
CRIMES CONTRA O MEIO AMBIENTE E AÇÕES DO MINISTÉRIO PÚBLICO NO MUNICÍPIO DE MOSSORÓ - RN NO PERÍODO DE 2013 A
} 2017

\section{Crimes against the environment and public prosecutor's actions in the municipality of Mossoró - RN in the period from 2013 to 2017}

\author{
Marco Lunardi Escobar \\ Professor da Universidade do Estado do Rio Grande do Norte \\ marcoescobar@uern.br \\ Raimundo Alberto Costa Queiroz \\ Mestre em Geografia pela UERN; Professor de Geografia na Rede Estadual do Rio Grande do Norte \\ aubertoqueiroz@gmail.com
}

Artigo enviado para publicação em 27/01/2019 e aceito em 26/05/2019

DOI: $10.12957 /$ tamoios.2019.39697

\begin{abstract}
Resumo
Os impactos ambientais no município de Mossoró/RN é um dos temas mais debatidos pela academia, orgãos governamentais e a sociedade. Nesse contexto, o principal objetivo deste trabalho é demonstrar que tipos de possíveis crimes ambientais foram praticados no município de Mossoró/RN, com recorte temporal de 2013 a 2017 e quais as ações desenvolvidas pelo Ministério Público na tentativa de combater estas ocorrências. A pesquisa é um estudo de caso, de cunho quanti-qualitativa, que adota o método indutivo. Utilizou-se revisão bibliográfica, pesquisa documental, levantamento de informações, através da observação de campo e junto à órgãos públicos municipais e estaduais envolvidos com a questão ambiental, além de entrevistas com alguns representantes de instituições de proteção ambiental. A pesquisa quantificou uma classificação das infrações em uma análise de 91 processos penais ambientais. Constatou-se que o Ministério Público se mostra atuante, por desenvolver um importante trabalho no combate aos crimes ambientais que foram praticados no município, seja no âmbito repressivo ou preventivo, apesar da existência de fatores, que limitaram a sua atuação, como por exemplo o fato dos órgãos de fiscalização ambiental apresentarem deficiências no tocante a estrutura e ao número reduzido de efetivo.
\end{abstract}

Palavras-chave: Meio ambiente, crimes ambientais; Ministério Público; município de Mossoró/RN.

\begin{abstract}
The environmental impacts in the municipality of Mossoró / RN is one of the themes are discussed more by academy, government agencies and society. In this context, the main objective of this work is to demonstrate what types of possible environmental crimes were practiced in the municipality of Mossoró / RN, with the temporary clipping of 2013 to 2017 and which actions developed by the State and Federal Public ministry in an attempt to combat these occurrences. The research is a case study of quantitative and qualitative nature that adopts the inductive method. It was used bibliographical review, documentary research, information gathering, through field observation and with the municipal and state public agencies involved with the environmental issue, as well as interviews with some representatives of environmental protection institutions. The research quantified a classification of offenses in an analysis of 91 environmental criminal proceedings. It was found that the Public Ministry it shows acting for developing an important work of combat against environmental crimes that were practiced in the municipality, whether in the repressive or preventive scope, despite the existence of factors, which limited its operations, for example, the fact that the environmental inspection agencies that operates in the study area have deficiencies in relation to the structure and the reduced number of personnel.
\end{abstract}

Keywords: environment, environmental crimes, Public Ministry, municipality of Mossoró / RN. 


\section{Introdução}

Vive-se hodiernamente em uma sociedade urbana industrial, que parece priorizar a qualquer custo o desenvolvimento econômico desenfreado, pouco se levando em consideração os danos ambientais que essa postura produtiva cartesiana pode ocasionar ao meio ambiente e a sadia qualidade de vida humana.

Segundo Milton Santos (2013), com a mecanização do planeta a natureza é artificializada e, unificada pela história para beneficiar o setor privado, público e classes hegemônicas. A sociedade de consumo e o modelo de desenvolvimento adotado pelos países ricos determinaram nas relações do homem com o meio ambiente um caráter extremamente agressivo.

Uma consequência desse modelo de sociedade insustentável do ponto de vista ambiental é sem dúvida a degradação do meio ambiente à nível local e global, visto que os problemas relacionados a degradação ambiental ultrapassam as fronteiras e limites dos territórios politicamente definidos.

Foi nesse contexto de degradação do meio ambiente à nível local, nacional e global, que conforme Camargo (2003) e Mendonça (2007) a partir da segunda metade do século XX, a humanidade passou a reconhecer a verdadeira necessidade de preservação e conservação do meio ambiente para o futuro da humanidade, incorporando nessa preocupação questões relacionadas aos aspectos sociais, políticos, ecológicos e econômicas, com o uso racional dos recursos naturais.

Foi, também nesta mesma conjuntura, que na busca de dirimir o conflito homem natureza, surgiu o ramo do Direito Ambiental, que é uma ciência jurídica vocacionada a estudar, analisar e discutir as questões relacionadas aos problemas ambientais e sua relação com o ser humano, visando a proteção do meio ambiente e as condições da melhoria de vida no planeta Terra (SIRVINSKAS, 2017).

Foi a partir dos anos 60 do século passado, que os países começaram a editar normas jurídicas mais rígidas para a proteção do meio ambiente. A função primordial desse ramo do direito é promover a organização da forma como a sociedade utiliza seus recursos ambientais, sendo um dos mais importantes instrumentos de intervenção nas relações entre o homem e o mundo (ANTUNES, 2017).

Nesta perspectiva, o Direito Ambiental possui uma perceptível ligação interdisciplinar com a Geografia, na medida em que, assim como a Geografia se preocupa em estudar a relação homem/meio, o Direito Ambiental, também tem esse interesse. $\mathrm{O}$ que muda é apenas o enfoque dado ao estudo. A Geografia estuda a relação homem/meio se preocupando em compreender e explicar o processo de produção e reprodução do espaço geográfico e o Direito Ambiental, foca sua análise na regulamentação dessa relação, visando a sustentabilidade para as presentes e futuras gerações. Como enfatiza Machado (2017, p. 59) "Não basta viver ou conservar a vida. É justo buscar e conseguir a "qualidade de vida".

Segundo Souza (2013), os estudos recentes a respeito da relação entre a Geografia e o Direito tem se mostrado proveitoso, na medida em que revela a interligação complexa existente entre o sistema jurídico com o aspecto material e simbólico do espaço, das paisagens e dos territórios.

A geografia do Direito Ambiental se fundamenta tanto nos termos legais como, também, nos discursos doutrinários e da jurisprudência, bem como nos procedimentos de aplicação do Direito. Enfim, por meio do Direito Ambiental, o Estado impõe a realização de determinadas condutas em relação ao meio ambiente, estabelece qualificações específicas para o espaço e, dessa maneira, promove a produção do espaço por meio jurídico (SOUZA, 2016). 
Caracteriza-se a pesquisa neste contexto, por possuir um cunho interdisciplinar, visto que a mesma busca estabelecer um diálogo entre a Geografia e o Direito Ambiental. Diálogo este, que de acordo com Souza (2015) é possível, visto que existe uma geografia no Direito Ambiental, que influencia na aplicação desse ramo do Direito, por meio da regulamentação da relação do homem com o meio ambiente de modo a permitir, condicionar ou proibir determinadas condutas com base no entendimento jurídico sobre este meio.

Segundo Fiorillo (2017) os crimes ambientais são condutas que levando em consideração a repercussão social que causam, foram erigidas pelo legislador à categoria de tipos penais, trazendo como consequência para o agente causador sanções como: multas, restrições de direitos e até mesmo a privação de liberdade.

Os crimes ambientais, nesta perspectiva, representam ações ou omissões praticadas pelo ser humano, no processo de produção e reprodução do espaço geográfico, que ocasionam danos ao meio ambiente, seja ele, natural, artificial ou cultural.

De acordo com Conte e Fiorillo (2017) os crimes ambientais e as suas respectivas sanções objetivam assegurar aos seres humanos o acesso ao direito fundamental assegurado constitucionalmente, que consiste em garantir um ambiente em sentido amplo para todos, de modo a promover a vida em todas as suas complexas manifestações, visto que um meio ambiente equilibrado se encontra nitidamente relacionado à dignidade do ser humano e as diversas manifestações da vida.

Frente à esta conjuntura de agressões constantes ao meio ambiente, provocadas pela ação antrópica, que é marcada a sociedade atual, seja à nível local, nacional ou global, estando neste contexto incluído o município de Mossoró/RN, surge o objetivo desta pesquisa, que é mostrar a luz do ordenamento jurídico brasileiro, que tipos de crimes ambientais foram praticados no município de Mossoró/RN, entre o período de 2013 a 2017 e, quais as ações desenvolvidas pelo Ministério Público Estadual e Federal, na tentativa de combater estes delitos

A expansão urbana do município de Mossoró/RN ocorrida nas últimas décadas, que se encontra relacionada com o dinamismo econômico gerado pelas atividades salineira, petrolífera, pela fruticultura irrigada e mais recentemente pelo desenvolvimento do mercado imobiliário, tem provocado transformações significativas na paisagem urbanística desta cidade (ROCHA, 2005). Transformações essas que tem provocado inúmeros impactos ao meio ambiente e, consequentemente a qualidade de vida do povo mossoroense.

Essa expansão urbana acelerada de Mossoró, ocorreu em um curto período de tempo e, não foi devidamente acompanhada da necessária preservação e cuidado para com o meio ambiente, o que vem contribuindo para a ocorrência de uma série de problemas ambientais neste município, tanto na zona urbana como, também, na rural.

De acordo com Sales, Grigio e Silva (2013) a expansão urbana acelerada, sem o devido planejamento e as pressões antrópicas sobre os recursos naturais tem provocados riscos e o surgimento de zonas de vulnerabilidade socioambiental no município.

Levando em consideração a existência de poucos trabalhos acadêmicos relacionados aos crimes ambientais praticados no município de Mossoró/RN, tendo sido identificado apenas três: (TOMAS, 2004), (OLIVEIRA; QUEIROZ, 2009) e (FERNANDES, 2014), acredita-se que esta pesquisa será mais um estudo científico a somar aos poucos que já existem sobre essa temática no município.

Nesse contexto, justifica-se o presente estudo por ser um trabalho que que se propõem a mostrar para sociedade os principais crimes ambientais que atingem $o$ município de Mossoró/RN na atualidade e o que o Estado por meio de uma de suas 
instituições permanentes essencial a sua função jurisdicional tem feito para combater esses delitos.

\section{Delimitação e caracterização da área de estudo}

A área de estudo desta pesquisa (figura 01), corresponde ao território do município de Mossoró, que é uma das 167 unidades administrativas do Rio Grane do Norte, localizado na Mesorregião Oeste Potiguar deste Estado.

Figura 01 - Mapa de localização da área de estudo.

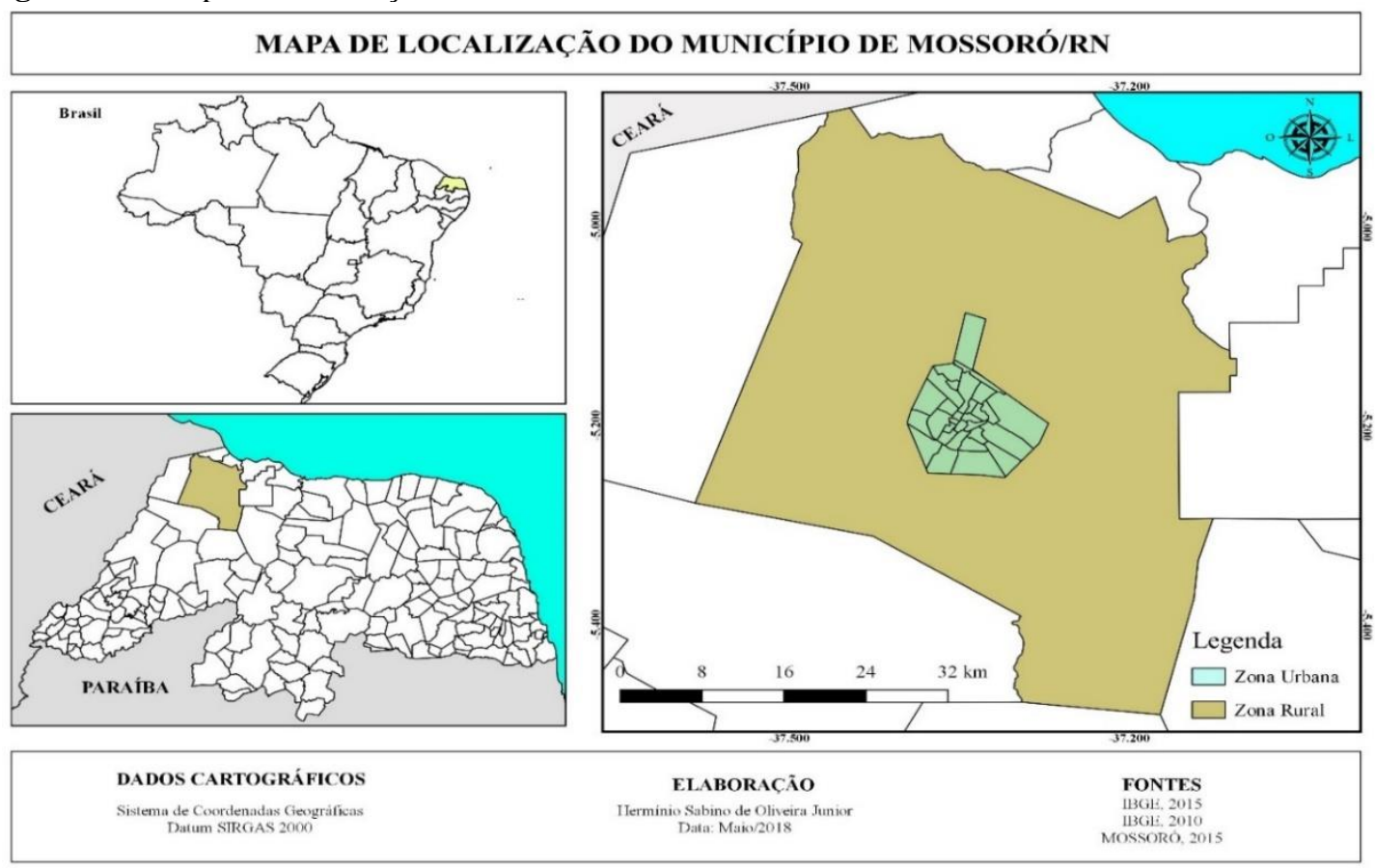

Fontes: (IBGE, 2010); (IBGE, 2015); (MOSSORÓ, 2015). Elaborado por Hermínio Sabino de Oliveira Junior (2018).

A referida área, engloba tanto a zona urbana, como também, a zona rural deste município, possuindo uma dimensão territorial de 2.099,333 $\mathrm{km}^{2}$ (IBGE, 2017a). Localiza-se o município, entre as coordenadas geográfica $5^{\circ} 11^{\prime} 15^{\prime}$ ' de latitude Sul e $37^{\circ}$ 20'39' de longitude Oeste a uma altitude média de 16 metros acima do nível do mar (IDEMA, 2008).

Conforme aborda Grigio e Diodato (2011, p. 100) “[...] o município de Mossoró apresenta clima quente e seco durante todo o ano, situação que é assinalada por estar sob influência do clima tropical semiárido da região Nordeste do Brasil e pela proximidade da linha do Equador". No tocante a flora, há três tipos diferentes de vegetação em Mossoró/RN, que são: caatinga hiperxerófila, carnaubal e a vegetação halófica (IDEMA, 2008).

De acordo com o último Censo do Instituto Brasileiro de Geografia e Estatística - IBGE, de 2010, a população deste município era de 259.815 habitantes, apresentandose como sendo o $2^{\circ}$ (segundo) município mais populoso do Estado e o $95^{\circ}$ (nonagésimo quinto) do Brasil. Dos 259.815 habitantes do município, 91,3\% vivem na zona urbana e apenas 8,7 na zona rural (IBGE, 2010). Ainda de acordo com o IBGE em 2017, este município, possuía uma população estimada de 295.619 habitantes (IBGE,2017b). 


\section{Materiais e métodos utilizados}

O presente artigo, trata-se de uma pesquisa científica aplicada, entendida como aquela que faz uso dos conhecimentos já sistematizados, com o objetivo de solucionar ou explicar problemas organizacionais do ser humano. Quanto à finalidade, classifica-se a mesma, como descritiva e exploratória, e quantos aos meios utilizados é do tipo documental, bibliográfica e de campo (GIL, 2006).

Adota a mesma o método indutivo, pois busca, a partir da análise de constatações particulares ou menos geral da realidade concreta, chegar a uma conclusão em enunciado mais geral (RUIZ, 2002), (DIEHL; TATIN, 2004) sobre quais tem sido as ações desenvolvidas pelo Ministério Público Estadual e Federal do Rio Grande do Norte para combater os crimes ambientais que foram praticados no município de Mossoró/RN, entre o período de $1^{\circ}$ de janeiro de 2013 a 31 de dezembro de 2017.

Trata-se de uma pesquisa do tipo quanti-qualitativa, pois em seu direcionamento metodológico voltou-se, tanto para a pesquisa bibliográfica a respeito do assunto estudado, como, também, observação de campo, pesquisa documental, entrevistas e o levantamento de informações (dados secundários), junto a alguns órgãos públicos municipais, estaduais e federais, com atuação direita ou indireta na área ambiental no município de Mossoró, como: o Instituto Chico Mendes de Conservação da Biodiversidade - ICMBio; a Secretaria Executiva de Meio Ambiente e Urbanismo do município de Mossoró/RN - SEMURB; o $3^{\circ}$ Pelotão da Companhia Independente de Proteção Ambiental da Polícia Militar do Rio Grande do Norte - CIPAM; o Escritório Regional do Instituto Brasileiro de Meio Ambiente e Recursos Naturais Renováveis IBAMA e o Centro Integrado de Operações de Segurança Pública - CIOSP, da Secretaria de Estado da Segurança Pública e da Defesa Social do Rio Grande do Norte - SESED.

Para se identificar os crimes ambientais praticados no Município de Mossoró/RN, no período estudado, compreendido entre 01 de janeiro do ano de 2013 a 31 de dezembro do ano de 2017, foi realizada uma pesquisa documental nos processos penais ambientais em tramitação, distribuídos neste lapso temporal, na Justiça Estadual TJRN e Federal do Rio Grande do Norte - JFRN. Realizada a identificação desses processos foi feita a consulta física em cada um deles. Este trabalho, é, portanto, nesta perspectiva, uma pesquisa documental ou de fontes primárias, onde os dados foram coletados por meio da documentação indireta (LAKATOS; MARCONI, 2009).

Adicionalmente à pesquisa bibliográfica, ao levantamento de dados secundários, e à pesquisa documental, foi realizado entrevistas com o juiz de direito do $4^{\circ}$ Juizado Especial Civel, Criminial e da Fazenda Pública da Comarca de Mossoró, com o Promotor titular da $3^{\text {a }}$ Promotoria de Justiça, com atribuições na defesa do meio ambinete, que representa o Ministério Público Estadual, com um dos dois Procuradores da República no Município de Mossoró, que representa o Ministério Público Federal e também, com os representantes legais, do Instituto Chico Mendes de Conservação da Biodiversidade ICMBio; da Secretaria Executiva de Meio Ambiente e Urbanismo do município de Mossoró/RN - SEMURB; do $3^{\circ}$ Pelotão da Companhia Independente de Proteção Ambiental da Polícia Militar do Rio Grande do Norte - CIPAM e um dos Analistas Ambientais do Escritório Regional do Instituto Brasileiro de Meio Ambiente e Recursos Naturais Renováveis - IBAMA, localizado em Mossoró.

As entrevistas realizadas foram do tipo individual, que segundo Vergara (2009, p. 06). "é a que se estabelece entre um entrevistador e um entrevistado" e quanto à estrutura, as entrevistas foram do tipo semiaberta, que é aquela que possui um roteiro previamente estruturado, mas que, ao contrário da estrutura fechada, que não admite 
nenhum tipo de alteração, permite que o entrevistador faça inclusões, exclusões, mudanças em geral nas perguntas e até explicações ao entrevistado (VERGARA, 2009).

Metodologia semelhante foi empregada por Lima (2017). Ao analisar os crimes ambientais no município de Serra/ES, abordando as ações e contradições dos agentes envolvidos no combate a estes delitos, este autor fez uso da pesquisa bibliográfica e o levantamento de dados em processos penais ambientais, junto às Varas Criminais do Fórum deste município no Espírito Santo. Ao verificar que os resultados obtidos pelo autor permitiram uma ampla análise, confirmou-se que este método seria o mais adequado neste estudo

\section{Resultados}

Com base na pesquisa realizada, identificou-se no município de Mossoró/RN, uma série de problemas ambientais, ocasionados pela ação antrópica, que representam em sua maioria infrações, inclusive de natureza penal, visto que, muitas das ações humanas que provocam esses impactos negativos no meio ambiente, são ocasionadas por condutas criminosas praticadas por pessoas físicas ou jurídicas.

É possível que esses crimes ambientais que são praticados constantemente neste município, sejam uma ameaça para sociedade mossoroense, visto que um meio ambiente ecologicamente equilibrado é uma condição indispensável para uma sadia qualidade de vida.

Esses crimes ambientais foram registrados por meio de uma pesquisa documental, que identificou um total 91 processos penais ambientais em tramitação na Justiça Estadual e Federal do Rio Grande do Norte, no município de Mossoró/RN, relativos a delitos dessa natureza praticados neste município entre o período de 2013 a 2017.

\section{A apresentação dos processos segundo a Justiça onde tramitam e os tipos de autuados}

Dos 91 processos penais ambientais, distribuídos no período de 2013 a 2017, em razão de crimes ambientais praticados no município de Mossoró/RN, entre os anos de 2013 a 2017, 88 deles, o equivalente a 96,7\%, foram encontrados tramitando na Justiça Estadual e 03 no âmbito da Justiça Federal, representado nesse contexto apenas 3,3\% dos processos consultados.

A razão da notória predominância do número de processos penais ambientais encontrados na Justiça Estadual do Rio Grande do Norte - TJRN, decorre do fato de que no Brasil a competência para o julgamento de crimes contra o meio ambiente em regra é da Justiça Estadual e apenas residualmente esta competência é da Justiça Federal em casos em que o crime ambiental é praticado em face de bens e serviços ou interesse da União, ou de suas entidades autárquicas ou empresas pública, nos termos da constituição Federal de 1988 (BRASIL, 1988).

Do universo dos 91 processos penais ambientais consultados, foram identificados 117 autuados pela prática de crimes contra o meio ambiente no município de Mossoró/RN. É preciso enfatizar, que o número de autuados é maior do que o número de processos em razão do fato de que em alguns dos processos consultados haviam mais de um autuado. Dos 117 autuados nestes processos, 107 foram pessoas físicas, o que representou aproximadamente $91,45 \%$ desse total e, apenas 10 pessoas jurídicas, representando aproximadamente $8,55 \%$ dos autuados 
Diante dos dados, observa-se que quem mais praticou crimes ambientais no município de Mossoró/RN, entre os anos de 2013 e 2017, foram as pessoas físicas, visto que representaram $91,45 \%$ dos autuado, enquanto as pessoas jurídicas (empresas) representaram apenas aproximadamente $8,55 \%$ dos autuados.

\section{Perfil social das pessoas físicas autuadas nos processos 91 processos consultados}

A partir da tabulação e análise dos dados levantados nos 91 processos consultados na pesquisa documental, ainda em tramitação no Poder Judiciário no ano de 2018, relacionados a crimes contra o meio ambientes praticados no município de Mossoró/RN, entre os anos de 2013 a 2017, foi possível, inclusive, traçar um perfil social dos autuados.

Tratam-se em sua maioria de pessoas físicas alfabetizadas $(96,16 \%)$, do sexo masculino (89,71\%), solteiros (45,79\%), entre uma faixa etária de 18 a 43 anos $(68,22 \%)$ e, quanto à profissão são em sua maioria: empresários, motoristas, comerciantes e agricultores, que causaram principalmente poluição sonora no período noturno, tinham em cativeiro animais silvestres e maus-tratos em animais.

Os dados relacionados ao nível de escolaridade das pessoas físicas autuadas, revelam notoriamente que do total das 107 pessoas físicas autuadas, apenas 3,74\% delas sãos analfabetas. As pessoas autuadas com Nível Superior, que em tese deveriam ter uma maior consciência ambiental em razão do nível educacional que possuem, representam $7,48 \%$ do total de autuados.

Crimes Ambientais praticados no município de Mossoró/RN, entre o período de 2013 a 2017: análise dos 91 processos penais ambientais segundo os artigos infringidos das Leis 9.605/98 e 6.766/79

A pesquisa documental, realizada nas Secretarias das Varas Criminais e dos juizados Especiais da Justiça Estadual - TJRN e Federal do Rio Grande do Norte - JFRN, permitiu se chegar ao resultado, com base nos dados dos 91 processos penais ambientais consultados, relacionados a crimes ambientais cometidos no município de Mossoró/RN, entre os anos de 2013 a 2017, que foram cometidos 97 crimes contra o meio ambiente neste município, no período estudado, já que em 06 desses processos, apura-se a prática de mais de um delito ambiental.

Pela pesquisa identificou-se nesse contexto, 13 artigos de leis infringidos, que provocaram direto ou indiretamente danos ao meio ambiente, ou seja, foi possível detectar a prática pela sociedade mossoroense de 13 crimes ambientais diferentes (gráfico 01), que totalizaram 97 infrações penais contra o meio ambiente, visto que a maioria desses 13 crimes ambientais foram praticados mais de uma vez. 
Gráfico 01 - Crimes ambientais praticados no município de Mossoró/RN, entre os anos de 2013 a 2017, com base nos 91 processos penais ambientais consultados na Justiça Estadual e Federal do Rio Grande do Norte.

\section{CRIMES AMBIENTAIS PRATICADOS NO MUNICÍPIO DE MOSSORÓ/RN,} ENTRE O PERÍODO DE 2013 A 2017

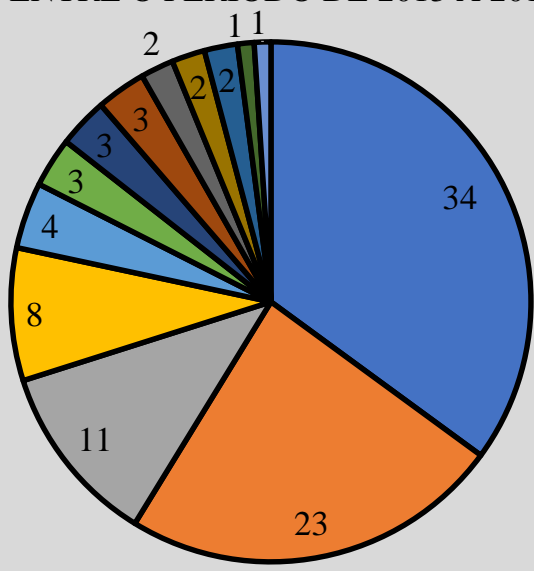

口Art. 54 da Lei n. 9.605/98 - Causar Poluição de qualquer natureza

口Art. 29 da Lei n. 9.605/98 - Ter em cativeiro ou transportar animal silvestre ilegalmente

口Art. 32 da Lei n. 9.605/98 - Praticar atos de maus-tratos em animais

口Art. 60 da Lei n. 9.605/98 - Construir, instalar ou fazer funcionar estabelecimento potencialmente poluidor sem licença

口Art. 56 da Lei n. 9.605/98 - Armazenar ou transportar substância tóxica, perigosa ou nociva ao meio ambiente

口Art. 46 da Lei n. 9605/98 - Transportar madeira irregulamente

口Art. 51 da Lei n. 9.605/98 - Utilizar motosserra em floresta e nas demais formas de vegetação sem licença ou registro

口Art. 50 da Lei n. 6.766/79 - Efetuar lotemaneto clandestino para fins urbanos sem autorização

口Art. 39 da Lei n. 9.605/98 - Cortar árvores em floresta considerada de preservação permanente sem permissão

口Art. 55 da Lei n. 9.605/98 - Extrair recusos minerais do tipo areia sem licença

口Art. 50 da Lei n. 9.605/98 - Destruir ou danificar floresta nativa

口Art. 34 da Lei n. 9.605/98 - Transportar espécime proveniente de pesca proibida

Fonte: Pesquisa documental realizada pelo autor na Justiça Estadual e Federal do Rio Grande do Norte (2018). Elaborado pelos autores (2018).

Pelo gráfico acima, observa-se que os 13 crimes ambientais diferenciados que foram praticados no município de Mossoró, entre os anos de 2013 a 2017, em ordem decrescente foram: causar poluição de qualquer natureza; ter em cativeiro ou transportar animal silvestre sem permissão, licença ou autorização; praticar atos de abuso, maustratos, ferir ou mutilar animal; construir, instalar ou fazer funcionar estabelecimento potencialmente poluidor sem licença; armazenamento ou transportar substâncias tóxica nocivas ao meio ambiente ilegalmente; transportar madeira irregularmente; utilizar motosserra em floresta e nas demais formas de vegetação sem licença ou registro; efetuar loteamento clandestino para fins urbanos sem autorização; cortar árvores em floresta considerada de preservação permanente sem permissão; extrair recursos minerais do tipo areia sem licença; destruir ou danificar vegetação nativa; transportar espécime proveniente de pesca proibida; dificultar a ação fiscalizadora poder público no trato das questões ambientais. 
Como se pode nitidamente observar no gráfico 01 , o crime de causar poluição de qualquer natureza, foi o com o maior número de ocorrência no município de Mossoró/RN no período estudado. Foram praticados 34 crimes de poluição, o que representa $35,05 \%$ de todas as infrações ambientais cometidas. Esta infração penal ambiental se encontra prevista no artigo 54, da Lei n. 9.605/98, que determina que "Causar poluição de qualquer natureza em níveis tais que resultem ou possam resultar em danos à saúde humana, ou que provoquem a mortandade de animais ou a destruição significativa da flora", é um delito com punição de pena de reclusão de um a quatro anos, e multa (BRASIL, 1998).

Diferentemente desta pesquisa, que constatou a predominância do crime de poluição no município de Mossoró/RN, estudo realizado por Lima (2017) acerca dos crimes ambientais praticados no município de Serra no Estado Espirito Santos, entre o período de 2005 a 2015, contatou a predominância neste município do crime de pesca proibida, realizada no período de defeso (artigo 34 da Lei n. 9.605/98), com 51 casos identificados de um total de 166 Ações Penais que serviu de base para o estudo. Foi identificado apenas um caso deste delito de pesca proibida no município de Mossoró com base na pesquisa documenta realizada.

Este fato demonstra como o tipo de ocorrência de crimes ambientais varia no espaço geográfico em razão de fatores diversos, seja de ordem natural, econômica ou culturais. No caso do município de Serra/ES, a predominância deste delito pode se justificar pela presença neste munícipio de lagoas, rios e do Oceano atlântico, que banha a parte leste do município, lugares estes onde a pesca é uma atividade econômica praticada com constância. Já no caso de Mossoró a pouca quantidade desse tipo de crime ambiental deve-se dar em virtude da pouca quantidade de reservatórios de águas superficiais, o município não ser banhado pelo mar e o rio Apodi-Mossoró, que corta município ser pouco utilizado para pesca.

A partir dos tipos de poluição: sonora, do solo, atmosférica, hídrica e visual, foi possível constatar que dos 34 Crimes de Poluição, 28 foram de Poluição Sonora; 03 de Poluição do Solo; 02 de Poluição Atmosférica e 01 de Poluição Hídrica. Observa-se que houve uma predominância significativa nos 34 casos de Crime de Poluição, da poluição do tipo sonora. Este tipo de poluição nos 28 casos detectados foi provocado em 23 deles por som automotivo e em 05 por som de estabelecimento comercial.

Nos 28 casos do crime de poluição detectados na pesquisa, provocados pela ação de ruídos oriundos de som automotivo e estabelecimentos comerciais, foi considerado como nível de critério de avaliação - NCA para ambientes externos, em decibéis (dB) para configuração técnica do delito adotado pelo $3^{\circ}$ Pelotão da CIPAM, com sede no Município de Mossoró/RN, que atuou em todos os casos e pelo Poder Judiciário, o determinado pela Lei Estadual n. 6.621/94, que dispõe sobre o controle da poluição sonora e condicionantes do meio ambiente no Estado do Rio Grande do Norte e dá outras providências (RIO GRANDE DO NORTE, 1994).

O fato da predominância do crime de poluição, provocado pela ação de ruídos oriundos de som automotivo e estabelecimentos comerciais, no total 28 casos, em detrimento dos demais outros delitos praticados no município de Mossoró/RN, entre o período de 2012 e 2017, pode ser explicado em virtude deste tipo de crime afetar diretamente o sossego físico e psicológico das pessoas, especialmente no período noturno, fazendo com que as mesmas se sentindo prejudicadas, liguem para o 190 da Polícia Militar para denunciarem a pratica desse tipo de crime ambiental. É válido salientar que em todos os 28 casos de crime de poluição identificados na pesquisa, provocados pela ação de ruídos oriundos de som automotivo e estabelecimentos comerciais todos eles foram praticados no período noturno. 


\section{Distribuição dos crimes ambientais praticados no município de Mossoró/RN, entre 2013 e 2017, segundo o tipo de crime praticado}

A Lei dos Crimes Ambientais (Lei n. 9.605/98), faz uma compartimentação das infrações penais ambientais, segundo o tipo de crime praticado, em 5 categorias, que são: crimes contra fauna, crimes contra a flora, crime de poluição e outros crimes ambientais, crime contra o ordenamento urbano e o patrimônio cultural e crimes contra a admiração ambiental (BRASIL, 1998).

Dos 97 crimes ambientais praticados no município de Mossoró/RN, entre os anos de 2013 e 2017, que foram identificados na pesquisa documental realizada na Justiça Estadual e Federal do rio Grande do Norte, em 91 processos penais ambientais, levando em consideração a divisão desses crimes, segundo o tipo de delito praticado, detectou-se que 48 deles foram relacionados ao crime de poluição e outros crimes ambientais; 37 aos crimes contra a fauna; 11 aos crimes contra a flora e, apenas 01 se relacionou aos crimes contra a administração Pública.

Pelos dados acima, observa-se que os crimes de poluição e outros crimes ambientais relacionados a poluição, foram os delitos com maior ocorrência em Mossoró, entre os anos de 2013 e 2017, com 48 casos; seguidos dos crimes contra fauna, com 37 casos; dos crimes contra a flora, com 14 casos e dos crimes contra a administração ambiental com apenas um caso.

\section{As ações Jurídicas desenvolvidas pelo Ministério Público no combate aos crimes ambientais praticados no município de Mossoró/RN, entre o período de 2013 a 2017}

Primeiramente, deve-se observar que o Ministério Público realiza atividades em três esferas do direito, no trato de questões ambientais, que são: a administrativa; a cível e a penal. Dessa forma, esta instituição fiscaliza as funções administrativas dos órgãos que fazem parte da administração pública e que atuam na proteção do meio ambiente, bem como facilita a responsabilização cível pelo dano ambiental, na medida em que trabalha como representante da coletividade, busca responsabilizar civilmente o infrator frente o dano ambiental cometido, além de atuar de maneira repressiva e punitiva em defesa do meio ambiente por meio da ação penal pública ambiental.

Neste contexto, esta pesquisa, aborda apenas a responsabilidade penal daqueles que praticaram crimes contra o meio ambiente no município de Mossoró, dentro do período delimitada pela pesquisa, compreendido entre janeiro de 2013 a dezembro 2017.

Sendo a maioria dos crimes ambientais praticados no município de Mossoró/RN, entre os anos 2013 a 2017, de menor potencial ofensivo, ou seja, crimes cuja pena máxima não é superior 2 anos, a competência para julgá-los é do Juizado Especial Criminal, de acordo art. 61, da Lei n. 9.099/95.

Nesse contexto, a solução para a maioria das infrações penais ambientais cometidas no município de Mossoró, no período delimitado pela pesquisa, se deram através da transação penal, prevista no artigo 72 e 76, da Lei n. 9.099/95, sempre exigindo, quando possível, a prévia composição do dano, que se faz realizar através de um termo de ajustamento de conduta - TAC, entre o autuado e o Ministério Público, a fim de que o dano seja reparado (BRASIL, 1995). Trata-se de um acordo para evitar que o processo se prolongue via judicial.

O instituto da transação penal é permitido nos crimes ambientais de menor potencial ofensivo, de modo que, na Audiência Preliminar, mesmo antes do autor do crime ambiental ter sido denunciado, pode o Ministério Público, propor o referido acordo, que representa uma espécie de aplicação imediata de pena restritiva de direitos ou multas, 
que deverá ser especificada na proposta. Neste contexto, caso o infrator aceite a proposta de transação penal, já que não é uma imposição, mas uma opção do mesmo, o Juiz homologa o acordo para que surta os devidos efeitos jurídicos.

Nos 91 processos penais ambientais consultados fisicamente na Justiça Estadual e Federal do Rio Grande do Norte, relativos a crimes ambientais praticados no município de Mossoró, entre os anos de 2013 a 2017, o Ministério Público propôs em 59 deles a transação penal. Dessa forma, a transação penal foi proposta pelo Ministério Público aos autuados, em $64,83 \%$ dos processos consultados.

Nesses 59 processos penais ambientais em que a transação penal foi ofertada pelo Ministério Público, em 34 deles, os autuados aceitaram a proposta de acordo; em 06 processos a transação não foi aceita pelos autuados; em 03 deles a proposta foi aceita, mas não foi cumprida e, em 16 processos, ainda se estava aguardando a realização de Audiência Preliminar, para que os autuados se manifestem se aceitam ou não a proposta de transação.

Nas propostas de transação penal ofertadas pelo Ministério Público e aceitas pelos autuados nos 34 processos acima referidos, com exceção dos casos em que os autuados foram pessoa jurídicas, sempre existiam duas opções para os autuados: A prestação de serviços à comunidade ou a prestação pecuniária.

Em 85,29\% desses 34 processos os atuados optaram pelo pagamento de prestação pecuniária e em apenas 14,71\% houve a opção pela prestação de serviço à comunidade. Com relação aos valores das prestações pecuniárias acordadas nas transações penais realizadas, estes são destinados pelo judiciário a entidades públicas com destinação social, a serem indicadas pelos Juízos onde os processos tramitam.

Mesmo quando o delito ambiental praticado não é de menor potencial ofensivo, e dessa forma a transação penal não é permitida, todavia existe, ainda, a possibilidade de aplicação de um outro instituto jurídico de acordo com o artigo 89 da Lei n. 9.099/95, que é a suspensão condicional do processo por dois ou quatro anos, quando a pena mínima cominada ao crime for igual ou inferior a 1 ano (BRASIL, 1995). Nos 91 processos consultados, o Ministério Público propôs a suspensão condicional do processo em 12 deles.

Na suspensão condicional do processo, o Ministério Público, ao oferecer a denúncia, poderá propor a suspensão do processo, pelo período de dois a quatro anos, desde que o acusado não esteja sendo processado ou não tenha sido condenado por outro crime. Neste lapso temporal o infrator é colocado a prova.

De acordo com o artigo $89, \S 1^{\circ}$ e $\S 2^{\circ}$ da Lei n. 9.099/95, ele terá que reparar o dano, salvo impossibilidade de fazê-lo e não poderá, sob pena de ter o benefício revogado: frequentar determinados lugares; ausentar-se da comarca onde reside, sem autorização do Juiz; comparecer mensalmente a juízo, para informar e justificar suas atividades, além de outras condições a que fique subordinada a suspensão, desde que sejam devidamente adequadas ao fato e à situação pessoal do acusado (BRASIL, 1995).

Já nas hipóteses em que não é possível nem a transação penal ou a suspensão condicional do processo, ou o autuado não aceitou nenhuma das propostas, que é uma opção do mesmo, é dever do Ministério Público denunciar o infrator ao Judiciário por meio da Ação Penal Ambiental, para que o Judiciário, após a análise das provas trazidas aos autos do processo, julgue se o denunciado praticou ou não o crime a ele imputado pelo Ministério Público, absolvendo-o ou o condenando. Nos 91 processos penais ambientais consultados fisicamente na Justiça Estadual e Federal do Rio Grande do Norte, o Ministério Público ajuizou 48 Ações Penais Ambientais, visando, apurar a responsabilidade penal dos infratores. Dessa forma, o Ministério Público denunciou os autuados, em 52,75\% dos processos consultados. 
Embora tenha sido identificado 03 casos de prisão em flagrante pela prática de crimes ambientais no município de Mossoró, em que os flagranteado foram liberados após o pagamento de fiança, não foi identificada na pesquisa nenhuma sentença condenatória privativa de liberdade em que o condenado teve ou terá de cumprir a pena aplicada pelo judiciário detido em um estabelecimento prisional, pois nos dois casos identificados na pesquisa em que houve condenação dos autuados pelo judiciário, em razão das penas aplicadas terem sido pequenas, um caso de 1 mês e 15 dias e um outro de 6 meses, os condenados irão cumpri-las em regime aberto, ou seja, soltos.

Do ponto de vista preventivo, segundo o titular da $3^{\text {a }}$ Promotoria da Comarca de Mossoró/RN, com atribuições na defesa do meio ambiente, o Ministério Público desenvolveu dois projetos, cujas partes de suas ações se efetivaram dentro do período delimitado desta pesquisa: O projeto Margem Viva e o projeto de Adequação Ambiental dos Postos de Gasolinas as normas ambientais.

O projeto Margem Viva, foi idealizado pela $3^{\text {a }}$ Promotoria de Justiça da Comarca de Mossoró, com atribuições na defesa do meio ambiente, no ano de 2008. O projeto se propõe a recuperar 148 hectares de áreas degradadas nas margens do rio Apodi-Mossoró, por meio de compensações ambientais obtidas através da assinatura de termos de ajustamento de conduta-TAC, entre o Ministério Público e empresas que atuam no setor salineiro. Pelo TAC, as salinas podem continuar atuando nas áreas que já foram degradadas, entretanto se comprometeram em recuperar outras regiões equivalentes às áreas ocupadas pelas mesmas. $\mathrm{O}$ documento que marcou o início das atividades foi assinado em 2010 (LAURENTINO; SOUZA, 2013).

Já o projeto de adequação ambiental dos postos de gasolinas as normas ambientais, instituído no município através da $3^{\mathrm{a}}$ Promotoria da Comarca de Mossoró/RN, no ano de 2013, firmou termos de ajustamento de conduta - TACs, com 40 dos 42 estabelecimentos em funcionamento no município. A atuação se desenvolveu em três etapas diferentes. A primeira foi a de elaboração de um diagnóstico da situação ambiental dos postos, onde os proprietários se comprometeram em contratar a Fundação Norte-rio-grandense de Pesquisa e Cultura - FUNPEC, para que os professores da Universidade Federal do Rio Grande do Norte - UFRN, verificassem se os estabelecimentos cumprem a legislação ambiental pertinente (MPRN, 2013).

$\mathrm{Na}$ segunda etapa desse mesmo projeto, o Ministério Público checou os resultados dos testes e, a partir desse momento, se fossem observadas irregularidades, seria dado um novo prazo para as devidas correções. Já na terceira etapa, viabilizou-se junto aos órgãos ambientais a emissão de um selo verde, próprio para os postos de combustíveis que tenha cumprido totalmente as obrigações assumidas nos termos de ajustamento de condutas (MPRN, 2013).

O Projeto, representa uma ação ampla do Ministério Público do Rio Grande do Norte, buscando que o os postos de combustíveis no Estado passem a cumprir o que determina a legislação, mais especificadamente a resolução n. 273/2000, do Conselho Nacional do Meio Ambiente - CONAMA, as determinações do IDEMA e o atendimentos às exigências técnicas da Associação Brasileira de Normas Técnicas - ABNT.

De acordo com o Promotor titular da $3^{\text {a }}$ Promotoria de meio ambiente este projeto ainda se encontra em andamento e metade dos postos de gasolina de Mossoró, no ano de 2018, já se encontram adequados ambientalmente.

Estudo monográfico realizado por Neiva (2015), chegou à conclusão de que o referido projeto contribuiu para defesa do meio ambiente, na medida em que, buscou mecanismos voltados para regularização da atividade de revenda de combustíveis na cidade de Mossoró. Atividade esta, considerada potencialmente poluidora, que pode 
ocasionar riscos diversos seja para o meio ambiente ou para saúde e segurança das pessoas.

De acordo com o comandante do $3^{\circ}$ Pelotão da CIPAM; com a Secretária Executiva de Meio Ambiente e Urbanismo do município de Mossoró/RN; com o Juiz de Direito titular do $4^{\circ}$ Juizado Especial Cível, Criminal, da Justiça Estadual da comarca deste município, com um dos Analista Ambiental do Instituto Chico Mendes de Conservação da Biodiversidade - ICMBio e atual Diretor do Parque Nacional da Furna Feia e com um dos Fiscais Ambientais do Escritório Regional do Instituto Brasileiro do Meio Ambiente e dos Recursos Naturais Renováveis - IBAMA, de Mossoró, o Ministério Público, tanto Estadual como o Federal, tem sido bastante atuante na defesa do meio ambiente neste município, desenvolvendo ações importantes com vistas ao enfrentamento dos crimes ambientais.

Por fim, conclui-se, com base nas informações colhidas na pesquisa documental e nas entrevistas realizadas com os representantes legais da CIPAM, SEMURB, IBAMA, ICMBio e do $4^{\circ}$ Juizado Especial, Cível, Criminal e da Fazenda Pública da Comarca de Mossoró, que o Ministério Público, entre o período de 2013 a 2017, desenvolveu um importante trabalho no combate aos crimes ambientais que foram praticados no município de Mossoró/RN, seja no âmbito repressivo ou preventivo, comportando-se portanto, como uma instituição atuante e comprometida com a defesa de um meio ambiente ecologicamente equilibrado, condição indispensável para uma sadia qualidade de vida.

\section{A distribuição espacial dos crimes ambientais praticados no município de Mossoró/RN, entre o período de 2013 a 2017.}

Um crime ambiental, não se trata apenas de um fenômeno meramente jurídico, mas também, de um fenômeno social e geográfico, visto que surge dentro do seio da sociedade, no contexto de produção e reprodução do espaço geográfico.

O espaço geográfico pode existir independentemente da ocorrência das infrações penais ambientais, mas estas não possuem existências desvinculadas do espaço geográfico. Dessa forma, os crimes ambientais acontecem no espaço geográfico e possuem uma espacialidade, visto que, se distribuem no espaço seguindo lógicas diversas. As espacialidades das infrações penais ambientais, representam formas específicas de apropriação e utilização do espaço geográfico, o que gera novas relações de produção.

Com base nos dados colhidos nos autos dos 91 processos penais ambientais consultados na Justiça Estadual e Federal do Rio Grande do Norte, foi possível identificar a localização geográfica dos locais de ocorrência dos 97 crimes ambientais que foram praticados no município de Mossoró/RN, entre o período de 2013 a 2017.

Quanto aos 74 crimes ambientais, que foram cometidos na zona urbana do município de Mossoró/RN, os dados dos autos dos processos permitiram fazer a localização de cada um dos delitos praticados levando em consideração os 30 bairros cadastrado da cidade de Mossoró.

A partir desses dados, colhidos por meio da pesquisa documental, foi confeccionado um mapa temático com a distribuição geográfica das 74 infrações penais ambientais que foram cometidas por pessoas físicas e jurídicas na zona urbana do município de Mossoró/RN, entre o período de 2013 a 2017 (figura 02).

Pelo mapa da figura 02 abaixo, pode-se observar, que entre os anos de 2013 a 2017, os 30 bairros cadastrados da cidade de Mossoró/RN, apresentam variações de números de práticas de crimes ambientais, que varia deste a nenhuma ocorrência até o número de 08 casos verificados. 
Figura 02 - Mapa da distribuição geográfica, por bairros, das 74 infrações penais ambientais identificadas na pesquisa documental, que foram práticas na zona urbana do município de Mossoró/RN, entre 2013 a 2017.

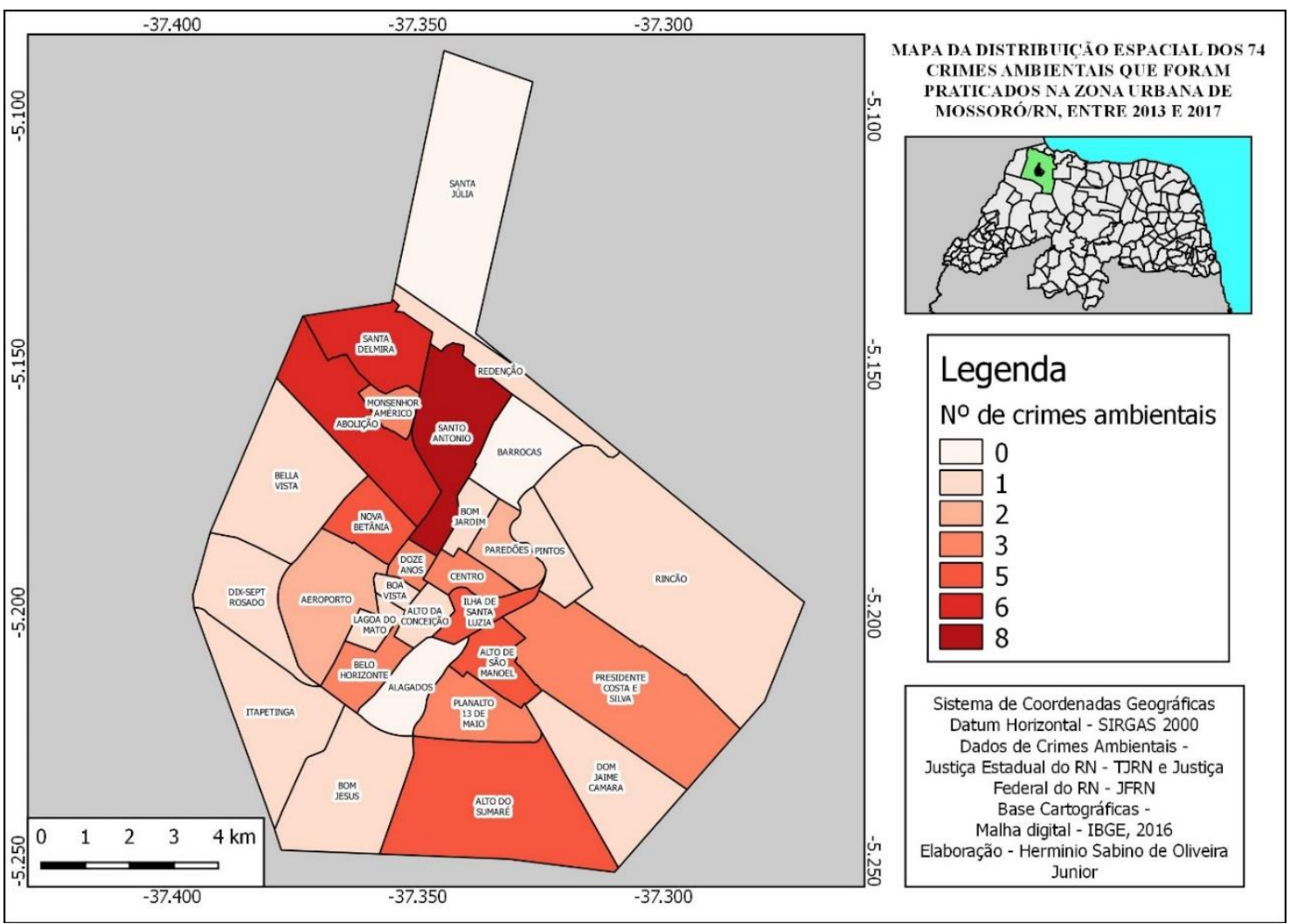

Fonte: Pesquisa documental realizada pelo autor na Justiça Estadual e Federal do Rio Grande do Norte (2018); (IBGE, 2016). Elaborado por Hermínio Sabino de Oliveira Junior (2018).

Dos 30 bairros, o que apresentou o maior número de ocorrências de crimes ambientais, no período delimitado pela pesquisa, foi o Santo Antônio, com um total de 08 ocorrências. Desses 08 casos de crimes ambientais praticados neste bairro, 02 foram de Poluição Atmosférica, sendo um ocasionado pela queima de lixo e outro por um forno de padaria que funcionava sem licença; 03 casos de Poluição Sonora, provocada por som automotivo; 02 casos de ter em cativeiro animal da fauna silvestre, do tipo pássaro, sem autorização da autoridade competente e 01 caso de fazer funcionar estabelecimento potencialmente poluidor, do tipo carvoaria, sem licença ambiental.

Em segundo lugar, com um total de 06 infrações penais ambientais, ficaram os bairros, Santa Delmira e Abolição. Em terceiro lugar, com 05 ocorrências de crimes, ficaram os bairros, Alto de São Manoel, Ilha de Santa Luzia e Nova Betânia. Em quarto lugar, com 03 casos praticados, ficaram os bairros, Belo Horizonte, Centro, Doze Anos, Monsenhor Américo, Planalto 13 de Maio e Presidente Costa e Silva. Em quinto lugar, com 02 casos ocorridos, ficaram os bairros, Aeroporto e Paredões. Já em sexto lugar, com apenas 01 caso de crime ambiental praticado, ficaram todos os demais outros bairros, com exceção dos bairros Barrocas e Santa Júlia, que não apresentaram nenhuma ocorrência de crimes contra o meio ambiente.

Quanto ao bairro Santo Antônio, que ficou em primeiro lugar em número de ocorrências de infrações penais contra o meio ambiente, totalizando 08 casos, a justificativa que pode ser dada para explicar este número se fundamenta no fato do referido bairro ser bastante extenso e muito violento. 
Estudo realizado por Silva, Grigio e Pimenta (2016), sobre a espacialização da criminalidade urbana no município de Mossoró/RN, entre os anos de 2010 a 2013, concluiu que nesse período ocorreram 618 homicídios no município de Mossoró, tendo 547 deles ocorridos na zona urbana e 55 na zona rural, tendo sido 16 casos não identificados. Dos 618 casos de homicídios, 116 foram praticados no Bairro Santo Antônio, que figurou na referida pesquisa como o bairro mais violento do município.

Uma análise da distribuição dos crimes ambientais praticados na zona urbana permite-se que se conclua que ocorreu uma concentração de infrações penais ambientais em seis bairros da cidade: Santo Antônio, Santa Delmira, Abolição, Alto de São Manoel, Ilha de Santa Luzia e Nova Betânia. Nestes 06 bairros apenas, foram praticados 19 crimes contra o meio ambiente, entre 2013 a 2017, o que representa um total de 25,67\% dos crimes ambientais praticados na zona urbana do município.

De acordo com Dias (2013) ao realizar um estudo sobre a especialização da vulnerabilidade social de Mossoró as áreas periféricas dos bairros Santo Antônio e Santa Delmira, por exemplo, apresentam vulnerabilidade social média alta a muito alta, o que demonstra a necessidade de o poder público dar uma maior atenção mais especial a essas áreas da cidade, no tocante as políticas públicas de cunho social.

Nesta perspectiva, a criminalidade relacionada ao meio ambiente em Mossoró, representa uma vulnerabilidade ambiental, que dificulta o acesso a uma sadia qualidade de vida dos cidadãos, visto que um ambiente ecologicamente equilibrado é uma condição indispensável para se ter uma sadia qualidade de vida.

Já quanto aos 23 crimes ambientais que foram praticados na zona rural, em 12 deles, nos próprios autos já estavam disponíveis as coordenadas geográficas do local de ocorrências dos crimes e, em 11 deles, as coordenadas geográficas estavam indisponíveis, entretanto havia informações do local em que os delitos ocorreram.

Diante desse contexto, foi feita uma averiguação de campo, com o uso de um aparelho GPS, do tipo, Garmim Etrex 20x, para demarcação das coordenadas geográficas desses 11 locais. Obtidas essas coordenadas foi possível produzir um mapa com a distribuição destes delitos na zona rural do município (figura 03).

Figura 03 - Mapa da distribuição geográfica dos crimes ambientais identificados na pesquisa documental, que foram praticados na zona rural do município de Mossoró/RN, entre 2013 e 2017.

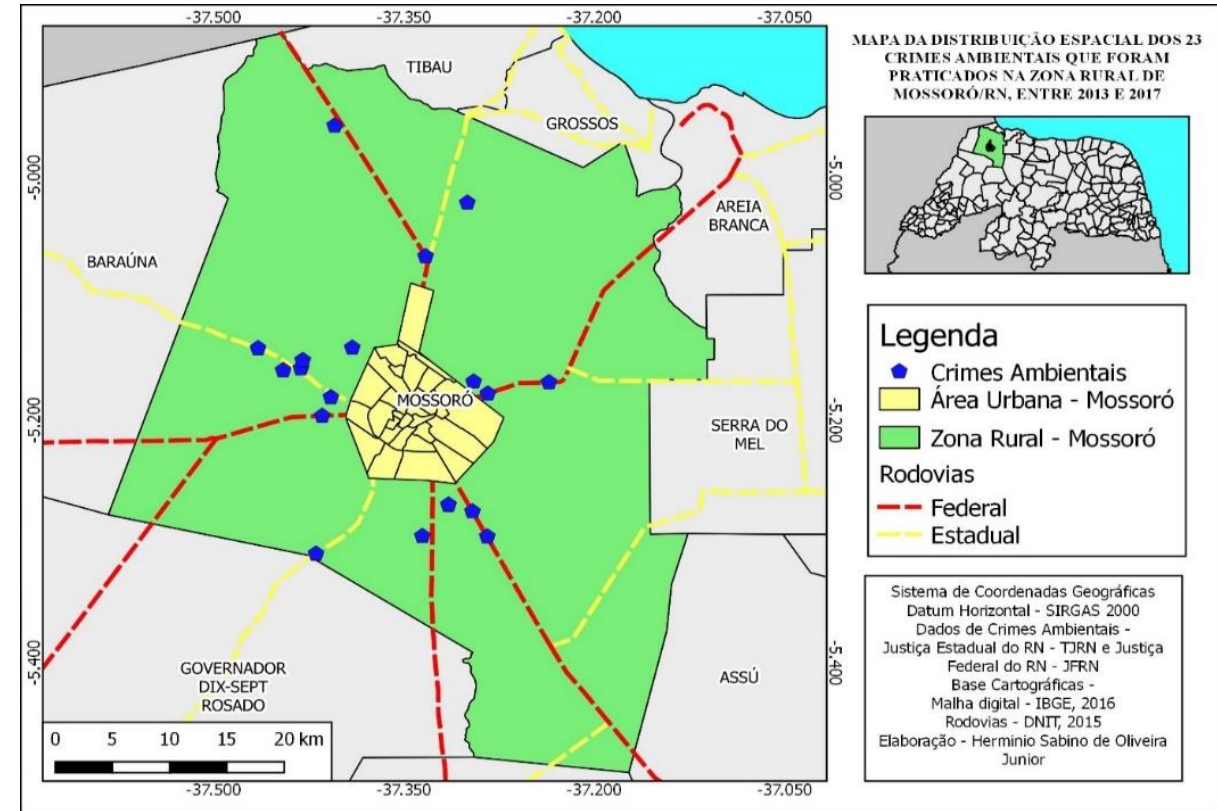

Fonte: Pesquisa documental realizada pelo autor na Justiça Estadual e Federal do Rio Grande do Norte (2018); (IBGE, 2016); (DNIT, 2015). Elaborado por Hermínio Sabino de Oliveira Junior (2018). 
A distribuição geográfica dos 23 crimes ambientais que foram praticados na zona rural do município no período delimitado na pesquisa, representada no mapa da figura 22, torna possível concluir que a maioria desses delitos foram cometidos nas proximidades da zona urbana de Mossoró, mais especificadamente em áreas próximas das Rodovias Federais e Estaduais (BR 304, 405 e 110 e as RN 117, 013 e 015).

Este fato pode se justificar em razão dessas áreas próximas do núcleo urbano no entorno das Rodovias Federais e Estaduais, serem espaços com maior fiscalização dos Órgãos ambientais fiscalizadores, que atuam no município, por serem áreas de mais fácil acesso, o que, consequentemente facilita a identificação das ocorrências de crimes ambientais praticados.

\section{Os fatores que facilitaram e dificultaram a atuação do Ministério Público no combate aos crimes ambientais praticados no município de Mossoró/RN, entre o período de 2013 a 2017}

Com base nos dados da pesquisa documental e, principalmente, nas informações colhidas por meio das entrevistas realizadas, foi possível identificar alguns fatores que, conforme os entrevistados, podem ter facilitado e dificultado a atuação do órgão ministerial no combate aos crimes ambientais praticados no município de Mossoró, entre o período de 2013 a 2017.

Identificou-se como fatores que facilitaram a atuação do Ministério Público no combate as infrações penais ambientais praticadas no município de Mossoró/RN, entre os anos de 2013 a 2017, os seguintes: o surgimento de uma incipiente consciência ambiental nos cidadãos mossoroenses; um sistema de coleta de denúncias, que preserva a identidade das pessoas que denunciam as infrações ambientais; as notícias crimes autuadas pelos órgãos de fiscalização ambiental chegarem em tempo hábil ao Ministério Público; a criação no município do $3^{\circ}$ Pelotão da Companhia Independente de Proteção Ambiental da Polícia Militar do Rio Grande do Norte - CIPAM e do Pelotão Ambiental da Guarda Civil Municipal de Mossoró - PAAM.

Com relação aos fatores que dificultaram a atuação do Ministério Público no combate as infrações penais ambientais praticadas no município de Mossoró/RN, entre os anos de 2013 a 2017, identificou-se com base na pesquisa documental e nas entrevistas realizadas, os seguintes: dificuldade na localização dos autuados; número reduzido do efetivo dos agentes de fiscalização, inexistência de uma delegacia especializada no combate aos crimes ambientais e o baixo nível de consciência ambiental do poder público e da sociedade de um modo geral.

Todos esses fatores, são entraves que acabam prejudicando direta ou indiretamente a atuação do Ministério Público no enfrentamento das infrações penais ambientais praticadas no município de Mossoró.

\section{Considerações Finais}

O município de Mossoró avança na criação de suas próprias leis ambientais, entretanto a gestão e planejamento do meio ambiente ainda são incipientes, a exemplo do sistema de saneamento básico, que ainda não foi concluindo e do Plano Diretor, que se encontra desatualizado, o que requer urgentemente a sua revisão. Consequência desse fato é o quadro diversificado de crimes ambientais identificados na pesquisa, que foram praticados no município de Mossoró durante o recorte temporal de 2013 a 2017, tanto por pessoas físicas como jurídicas, que representou um considerável número de infrações, agrupadas em 13 categorias de crimes diferentes. 
Quanto ao Ministério Público, restou evidenciado que o órgão ministerial tem se mostrado bastante atuante e comprometido com o combate aos crimes ambientais que são praticados na área de estudo, seja no âmbito preventivo ou repressivo, através de instrumentos processuais e extraprocessuais, que buscam apurar a responsabilidade penal daqueles que cometem infrações ambientais no município, embora esteja atrelado a uma série de limitações, que revelam as deficiências do poder do Estado para satisfação do bem comum.

A pesquisa ainda verificou que existem fatores que dificultam a atuação do Ministério Público, sendo o mais preocupante o número reduzido do efetivo dos agentes de fiscalização dos órgãos ambientais. $O$ órgão ministerial possui atuação limitada no combate os crimes ambientais em Mossoró, visto que o seu desempenho, depende e muito, da atuação dos órgãos de fiscalização ambiental com atuação na área de estudo, pois são estes órgãos que levam ao seu conhecimento as ocorrências de crimes contra o meio ambiente. Dessa forma, sem uma fiscalização eficiente desses órgãos a atuação do Ministério Público fica seriamente comprometida.

Sugere-se ao poder público, em suas diferentes esferas de governança, uma maior preocupação com os órgãos de fiscalização ambiental com atuação na área territorial do município, no sentido de destinar aos mesmos mais investimentos para melhor aparelha-los com recursos técnicos e humano, pois os poucos recursos técnicos e o número reduzido de efetivo desses órgãos na atualidade prejudicam a fiscalização ambiental e a atuação do Ministério Público e consequentemente estimula as práticas criminosas, que atentam contra o meio ambiente. Práticas essas que são um entrave para o bem-estar do povo mossoroenses, já que, um meio ambiente ecologicamente equilibrado, representa uma condição indispensável para uma sadia qualidade de vida da população.

Espera-se que os resultados obtidos nesta pesquisa possam servir de subsídio para os formuladores de políticas ambientais do poder público no planejamento das ações governamentais no município e que esta pesquisa possa proporcionar aos leitores, refletir sobre a temática proposta de forma a produzir outras discussões, bem como mais pesquisas voltadas à análise dos crimes ambientais que são cometidos diariamente em Mossoró e que este estudo contribua de alguma forma para os pesquisadores interessados no tema, sem, no entanto, ter a pretensão de esgotar o assunto, já que a questão ambiental é extremamente complexa e interdisciplinar.

\title{
Referências Bibliográficas
}

ANTUNES, Paulo de Bessa. Direito ambiental. 19. ed. São Paulo: Atlas, 2017.

\author{
BRASIL. Constituição (1988). Constituição da República Federativa do Brasil de \\ 1988. \\ Disponível
}

em:<http://www.planalto.gov.br/ccivil_03/constituicao/constituicaocompilado.htm

$>$. Acesso em 10 de fevereiro de 2018.

Lei Federal n. 9.099, de 26 de setembro de 1995. Dispõe sobre os Juizados

Especiais Cíveis e Criminais e dá outras providências. Disponível em:<http://www.planalto.gov.br/ccivil_03/leis/19000.htm>. Acesso em 22 de março de 2018 .

Lei Federal n. 9.605 de 26 de setembro de 1998. Dispõe sobre as sanções penais e administrativas derivadas de condutas e atividades lesivas ao meio ambiente, e 
dá outras providências. Disponível em: <http://www.planalto.gov.br/ccivil_03/leis/19605.htm>. Acesso em 22 de março de 2018.

CAMARGO, Ana Luiza de Brasil. Desenvolvimento sustentável: do pensamento único à consciência universal. Campinas, SP: Papirus, 2003.

CONTE, Christiany Pegorari; FIORILLO, Celso Antônio Pacheco. Crimes Ambientais. 2. ed. São Paulo: Saraiva, 2017.

DIAS, Gutemberg Henrique. Identificação da vulnerabilidade socioambiental na área urbana de Mossoró-RN, a partir do uso de técnicas de análises espaciais. 2013. 167 f. Dissertação (Mestrado em Ciências Naturais) - Faculdade de Ciências Exatas e Naturais da Universidade do Estado do Rio Grande do Norte. Mossoró/RN, 2013.

DIEHL, Astor Antônio; TATIN, Denise Carvalho. Pesquisa em ciências sociais aplicadas: métodos e técnicas. São Paulo: Prentice Hall, 2004.

FERNANDES, Narcelio Queiroz. Do direito ao silêncio sonoro: diagnóstico e análise da poluição sonora no município de Mossoró/RN. 2014. 71 f. Monografia (Bacharelado em Direito) - Faculdade de Direito da Universidade do Estado do Rio Grande do Norte. Mossoró/RN, 2009.

FIORILLO, Celso Antônio. Curso de direito ambiental brasileiro. 17. ed. São Paulo: Saraiva, 2017.

GIL, A. C. Como elaborar projetos de pesquisa. 4. ed. São Paulo: Atlas, 2006.

GRIGIO, Alfredo M.; DIODATO, Marco Antônio. Dimensões físico-ambiental. In: PESSOA, Zoraide et al. (Orgs.). Como anda Mossoró: análise da conjuntura sociourbana, ambiental e político-institucional. Natal: UFRN, 2011.

IDEMA. Instituto de Desenvolvimento Sustentável e Meio Ambiente. Perfil do município de Mossoró. Natal/RN, 2008.

IBGE Cidades. Perfil da cidade de Mossoró/RN: área da unidade territorial. Rio de Janeiro, 2017a. Disponível em: < https://cidades.ibge.gov.br/brasil/rn/mossoro/panorama >. Acesso em 12 de maio de 2018.

IBGE. Instituto Brasileiro de Geografia e Estatística. Estimativa populacional do IBGE de 2017. 2017b. Rio de Janeiro: IBGE, 2017b. Disponível em: <ftp://ftp.ibge.gov.br/Estimativas_de_Populacao/Estimativas_2017/estimativa_dou_201 7.pd>. Acesso em 10 de abril de 2018.

LAKATOS, Eva Maria; MARCONDI, Marina de Andrade. Metodologia do trabalho científico. 7. ed. São Paulo: Atlas, 2009.

LAURENTINO, Izabela Costa; SOUZA, Samir Cristiano. Uma análise do plano de recuperação de áreas degradadas com vegetação de mangue no rio Apodi-Mossoró do projeto margem viva. Revista Holos, RN, Ano 29 v. 3 p.161-170, 2013. Disponível 
em: <http://www2.ifrn.edu.br/ojs/index.php/HOLOS/article/view/1321/690>. Acesso em 30 de julho de 2017.

LIMA, Luiz Claudio. Os crimes ambientais no município de Serra - ES: ações e contradições dos agentes envolvidos. 2017, 152 f. Dissertação (Mestrado em Geografia) - Universidade Federal do Espírito Santo, Vitória, 2017.

MPRN. Ministério Público do Rio Grande do Norte. MP inicia projeto para adequação ambiental de postos em Mossoró. Natal/RN, 2013. Disponível em: < https://www.mprn.mp.br/portal/inicio/noticias/5772-5772-mp-inicia-projeto-paraadequacao-ambiental-de-postos-em-mossoro>. Acesso em 22 de junho de 2018.

MENDONÇA, Francisco de Assis. Geografia e meio ambiente. 8. ed. São Paulo: Contexto, 2007.

MACHADO, Afonso Leme. Direito ambiental brasileiro. 25. ed. São Paulo: Malheiros, 2017.

NEIVA, Monalisa Gomes. A atuação do ministério público em defesa do meio ambiente: um estudo de caso sobre o projeto de adequação dos postos de combustíveis no município de Mossoró/RN. 2015. 52 f. Monografia (Bacharelado em Gestão Ambiental) - Faculdade de Ciências Econômicas da Universidade do Estado do Rio Grande do Norte. Mossoró/RN, 2015.

OLIVEIRA, Marcos Antônio; QUEIROZ, Raimundo Alberto Costa. A poluição do rio Apodi-Mossoró (RN) e a ação intervencionista do Ministério Público. Artigo apresentado no IV Encontro Nacional da Anppas. Brasília/DF. 4, 5 e 6 de junho de 2008. Disponível em: <http://www.anppas.org.br/encontro4/cd/ARQUIVOS/GT6-518-100420080517230550.pdf >. Acesso em 10 de maio de 2018.

RIO GRANDE DO NORTE. Lei Complementar n. 6.621, de 12 de julho de 1994. Dispõe sobre o controle da poluição sonora e condicionantes do meio ambiente no Estado do Rio Grande do Norte e dá outras providências. Disponível em: $<$ http://www.mprn.mp.br/portal/inicio/meio-ambiente/meio-ambiente-material-deapoio/304-lei-no-6621-de-12-de-julho-de1994poluicao-sonora-no-estado-dorn?path=>.Acesso em: 18 de junho de 2018 .

ROCHA, Aristotelina Pereira Barreto. Expansão urbana de Mossoró (período de 1980 a 2004). Natal/RN: EDUFRN, 2005.

RUIZ, João Álvaro. Metodologia científica: guia para eficiência no estudo. 5. ed. São Paulo: Atlas, 2002.

SALLES, Maria Clara Torquato; GRÍGIO, Marcelo Alfredo; SILVA, Marcia Regina. Expansão urbana e conflito ambiental: uma descrição da problemática do município de Mossoró- RN - Brasil. Revista Soc. \& Natureza, Uberlândia, v. 25, n. 2, p. 291-290, maio/ago/2013. Disponível em:< http://www.seer.ufu.br/index.php/sociedadenatureza/article/view/14389/pdf >. Acesso em 10 de setembro de 2018. 
SANTOS, Milton. Técnica, espaço, tempo. Globalização e meio técnico-científicoinformacional. 5. ed., 1. reimpr. - São Paulo: Editora da Universidade de São Paulo, 2013.

SILVA, Camila Saiury Pereira. GRIGIO, Alfredo Marcelo.; PIMENTA, Rafaela Costa; Levantamento e espacialização da criminalidade urbana do município de MossoróRN. Revista Holos, RN, Ano 32 v. 3 p.352-362, 2016. Disponível em: <http://www2.ifrn.edu.br/ojs/index.php/HOLOS/article/view/4187/1503>. Acesso em 30 de julho de 2017.

SIRVINSKAS, Luiz Paulo. Manual de direito ambiental. 15. ed. São Paulo: Saraiva, 2017.

SOUZA, Jonas Dias de. A relação entre a Geografia e o Direito: notas bibliográficas. Revista do Departamento de Geografia - USP (Online), São Paulo, v. 25, p. 263-285, 2013. Disponível em:< https://www.revistas.usp.br/rdg/article/view/75184/78732>. Acesso em 22 de julho de 2018.

SOUZA, Jonas Dias de. Geografia e Direito ambiental: qual a relação? Artigo apresentado no XI Encontro Nacional da Associação Nacional de Pós-Graduação e Pesquisa em Geografia - ANPEGE, realizado em Presidente Prudente/SP, entre 9 a 12 de outubro de 2015.2 Disponível em:<http://www.enanpege.ggf.br/2015/anais/arquivos/23/630.pdf $>$. Acesso em $30 \mathrm{de}$ julho de 2018.

SOUZA, Jonas Dias de. Direito ambiental como questão geográfica. Revista Cadernos de Geografia. Belo Horizonte/MG. V. 26, n. 46, p. 299-313, 2016. Disponível em:< http://periodicos.pucminas.br/index.php/geografia/article/view/P.23182962.2016v26n46 p299/9509>. Acesso em 22 de julho de 2018.

TOMAS, Helen Vieira de Queiroz. A efetividade da legislação ambiental: o caso da cidade de Mossoró nos anos de 2003-2004. 2004. Monografia (Bacharelado em Direito) - Faculdade de Direito da Universidade do Estado do Rio Grande do Norte. Mossoró/RN, 2004.

VERGARA, Sylvia Constant. Método de coleta de dados de campo. São Paulo: Atlas, 2009. 